\title{
Uniportal subxiphoid approach for resection of an intra-thymic parathyroid adenoma: a case report
}

\author{
Massimo Castiglioni ${ }^{1}$, Wolfram Karenovics ${ }^{2}$, Frédéric Triponez $^{2}$, Benoît Bédat ${ }^{2}$ \\ ${ }^{1}$ Department of Thoracic Surgery, IRCCS MultiMedica, Milan, Italy; ${ }^{2}$ Department of Thoracic and Endocrine Surgery, University Hospitals of \\ Geneva, Geneva, Switzerland \\ Correspondence to: Massimo Castiglioni. Department of Thoracic Surgery, IRCCS MultiMedica, via Milanese, 300, 20099 Sesto San Giovanni (MI), \\ Italy. Email: massimo.castiglioni@multimedica.it.
}

\begin{abstract}
Ectopic parathyroid glands are frequently encountered. When patients develop hyperparathyroidism, a parathyroidectomy may be indicated. Normally, this is feasible through a cervical incision; however, a few patients may require a trans-sternal or trans-thoracic approach due to deeply located adenomas. Most surgeons currently use a thoracoscopic approach; however, this can cause postoperative neuropathic pain because of the trauma to the intercostal nerves. In the Video, we describe a uniportal subxiphoid approach for resection of an intra-thymic parathyroid adenoma causing hyperparathyroidism. We report the case of a 44-year-old woman who was referred for primary hyperparathyroidism. She had recurrent renal lithiasis, gastritis, fatigue and loss of concentration. Corrected serum calcium level was $2.9 \mathrm{mmol} / \mathrm{L}$ and parathormone $25 \mathrm{pmol} / \mathrm{L}$. A scintigraphy scan localized an ectopic adenoma in the anterior mediastinum, below the left innominate vein. Under general anesthesia, a subxiphoid transverse incision was made and the retrosternal space was entered. A GelPOINT ${ }^{\circledR}$ Mini advanced access platform was placed and all the thoracoscopic instrumentations were inserted through this single port. Carbon dioxide was insufflated. During dissection, the ectopic adenoma was localized inside the thymus gland. This was confirmed by intraoperative angiography with Indocyanine green and a subtotal thymectomy was then performed. Intraoperative parathormone levels confirmed biological cure of primary hyperparathyroidism. The patient was discharged with normal serum calcium level and parathormone, without any pain medication. Uniportal subxiphoid technique might be considered as valid alternative to the standard thoracoscopic resection, possibly resulting in more favorable outcomes.
\end{abstract}

Keywords: Ectopic parathyroid adenoma; thoracoscopic; uniportal subxiphoid approach; case report; GelPOINT $^{\circledR}$

Received: 21 July 2019; Accepted: 03 December 2019; Published: 05 April 2020.

doi: 10.21037 /jovs.2019.12.04

View this article at: http://dx.doi.org/10.21037/jovs.2019.12.04

\section{Introduction}

Ectopic parathyroid glands are encountered in approximately $15-20 \%$ of patients (1). Usually, these glands are distributed alongside the territory of embryologic migration, which extends from the laterocervical area to the deep mediastinum. When patients develop symptomatic hyperparathyroidism, radiologic localization of the hyperfunctioning adenoma is required and parathyroidectomy may be indicated. Surgical intervention is feasible through a cervical incision in most cases; however, up to $2 \%$ of patients will require a transsternal or trans-thoracic approach (2). In fact, most of the ectopic mediastinal adenomas are located in the neck region or in the superior mediastinum and can be removed using a cervical approach. Occasionally, the adenoma is located deeply into the mediastinum or chest being inaccessible through the neck. Thus, the anatomic position of the ectopic gland may favor the use of thoracic approaches as reported for adenomas located below the brachiocephalic vein or the aortic arch or in the anterior mediastinum at least $5 \mathrm{~cm}$ 


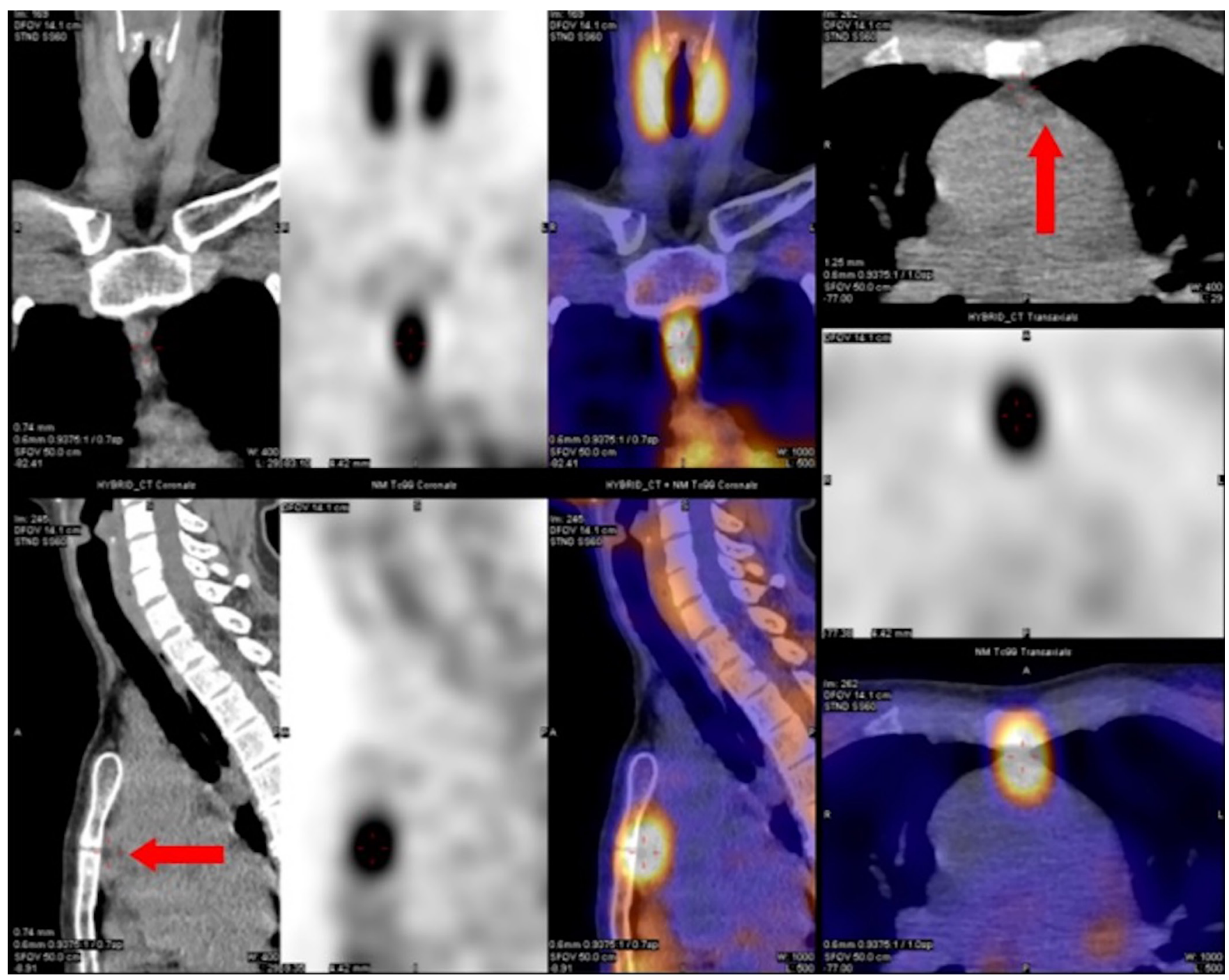

Figure 1 Scintigraphy scan with SPECT/CT using 123-iodine and 99-technetium sestamibi localizing the ectopic parathyroid adenoma in the anterosuperior mediastinum, behind the sternal angle (red arrow).

below the sternal notch (2). Minimally invasive techniques for mediastinal parathyroidectomy have recently shown similar outcomes compared to traditional open procedures, with significantly shorter length of hospital stay (3). Video-assisted thoracoscopic surgery (VATS) is the most common approach, however, neuromuscular injury caused by intercostal incisions and rib spreading is associated to higher risk of postoperative pain and morbidity (4).

\section{Case presentation}

We report the case of a 44-year-old woman who was referred to our institution for the treatment of primary hyperparathyroidism. She had a 10-year history of recurrent renal lithiasis, gastritis, progressively increasing fatigue and loss of concentration. Her history was unremarkable except for depression syndrome and negative family history of endocrinopathies was recorded. Physical examination was normal. Corrected serum calcium level was $2.9 \mathrm{mmol} / \mathrm{L}$ (normal range: $2.2-2.52$ ) and parathormone (PTH) level was $25 \mathrm{pmol} / \mathrm{L}$ (normal range: 1.1-6.8). A scintigraphy scan with single photon emission computed tomography/computed tomography (SPECT/CT) using 123-iodine and 99-technetium sestamibi localized an ectopic parathyroid adenoma in the anterior mediastinum, behind the sternal angle (Figure 1) 


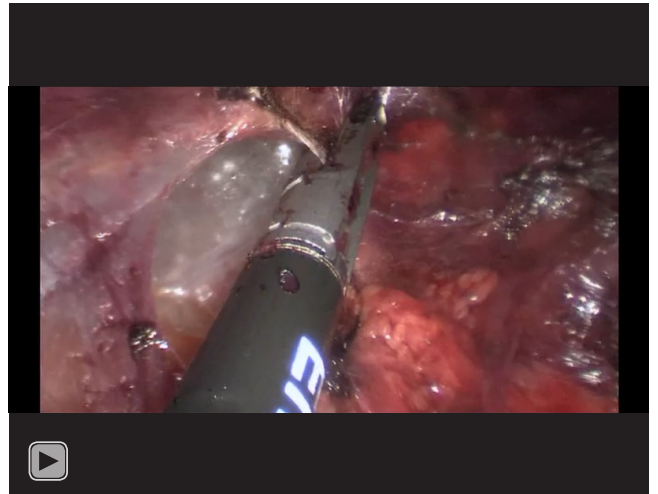

Video 1 Uniportal subxiphoid approach for resection of an intrathymic parathyroid adenoma: a case report (5).

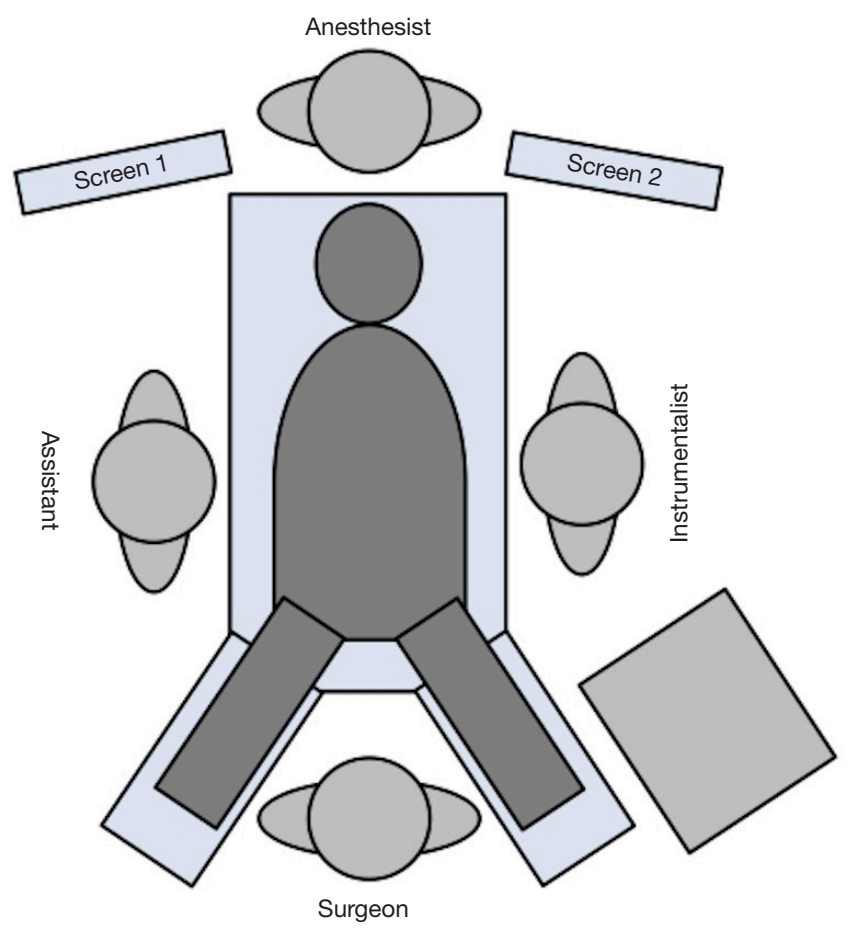

Figure 2 The patient is placed in the open-leg position. The surgeon stands between the patient's legs with the assistant surgeon on his left. The scrub nurse stands on the left side of the patient ensuring to place instruments in the right hand of the surgeon. Monitors are positioned at the patient's head, in front of the surgeon.

$45 \mathrm{~mm}$ below the sternal notch and $15 \mathrm{~mm}$ below the left innominate vein without any other suspicious location on neck ultrasonography and scintigraphy scan. The patient was offered a minimally invasive resection of the ectopic adenoma with a curative intent and she agreed to undergo

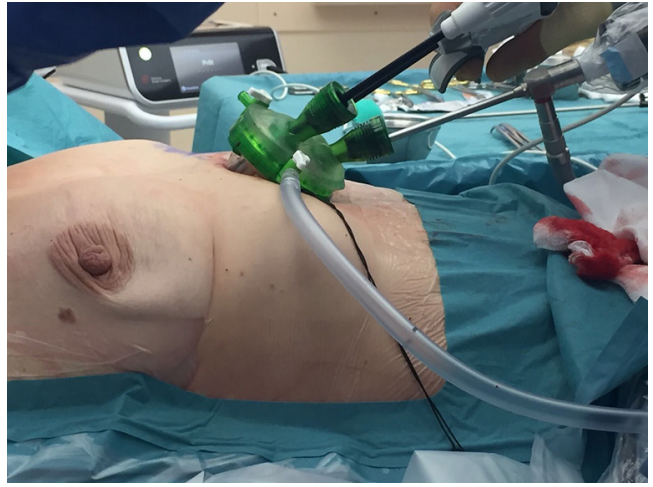

Figure 3 Installation of the GelPOINT ${ }^{\circledR}$ Mini platform with the camera port on the caudal side of the patient, the tissue-sealing device on the right side and the endoscopic grasper on the left side.

this procedure. All procedures performed in this study were in accordance with the Helsinki Declaration (as revised in 2013). Written informed consent was obtained from the patient for publication of this manuscript and any accompanying images.

\section{Surgical technique}

We performed a surgical resection of the ectopic adenoma by using a uniportal subxiphoid technique in this patient as shown in the video (Video 1). Under general anesthesia, a single lumen endotracheal intubation was used. Patient was placed in supine position with the arms alongside the body (Figure 2). A roll was positioned behind the shoulders to allow hyperextension of the neck. A single 3-cm transverse incision was made at the tip of the xyphoid process and the linea alba was incised. The retrosternal space was then entered leaving the xiphoid process in place. Initial blunt dissection was performed digitally, clearing the posterior side of the sternum from the pericardial fat pad. A GelPOINT $^{\circledR}$ (Applied Medical, CA, USA) Mini advanced platform was inserted (Figure 3). To improve visibility during mediastinal dissection, carbon dioxide $\left(\mathrm{CO}_{2}\right)$ was insufflated at $8 \mathrm{mmHg}$, with pressures ranging from 6 up to $10 \mathrm{mmHg}$. An angled $\left(30^{\circ}\right) 5$-mm thoracoscope and all thoracoscopic instruments were inserted through this single port. Enseal tissue-sealing device (Ethicon Endo-Surgery, Blue Ash, Ohio) was used during the procedure. Both pleural cavities were opened. After clearing the posterior face of the sternum, the pericardial fat pad along with all the mediastinal tissue between both phrenic nerves was dissected and separated en-bloc from the anterior face of 


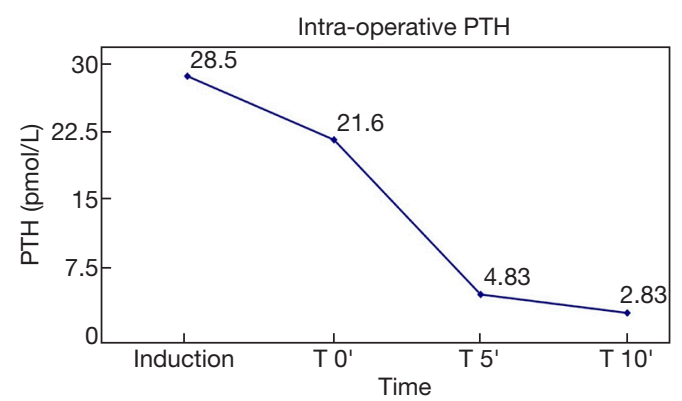

Figure 4 The graph shows intra-operative PTH levels at the time of induction of anesthesia $(28.5 \mathrm{pmol} / \mathrm{L})$ and after removal of the parathyroid adenoma at T 0' (21.6 pmol/L), T 5' (4.83 pmol/L) and T 10' (2.83 pmol/L).
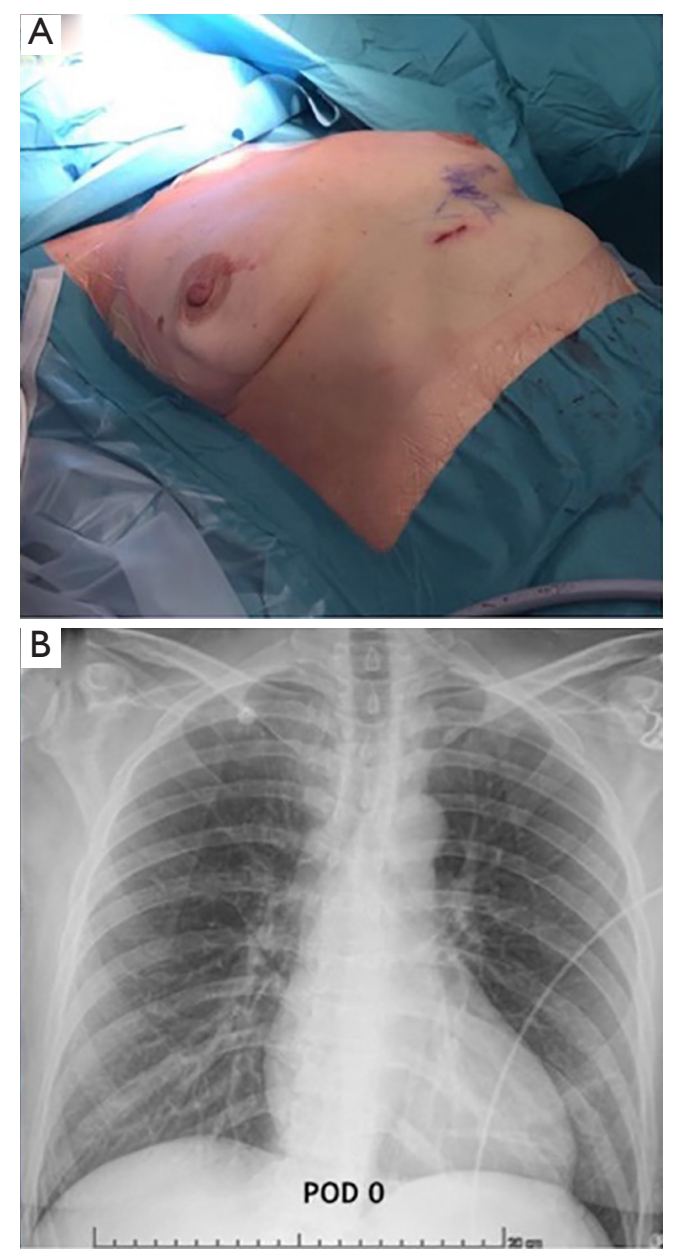

Figure 5 Postoperative wound (A) and chest-X-ray image (B) showing normal findings.

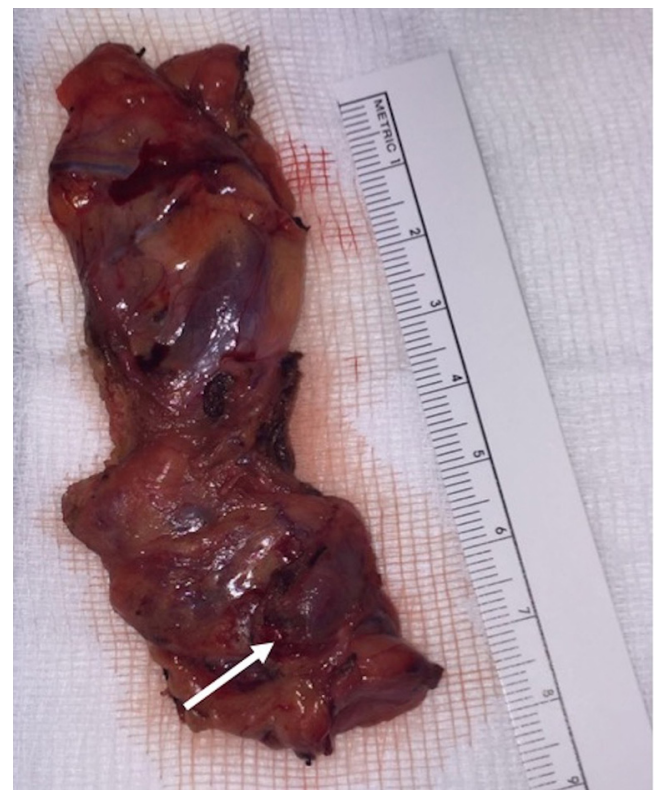

Figure 6 Surgical specimen with the parathyroid adenoma located inside the thymus gland (white arrow).

the pericardium. The mediastinal tissue was then retracted upward, thus visualizing the intra-thymic parathyroid adenoma inside the thymus gland; this was confirmed using intravenous Indocyanine green angiography. Then, a subtotal thymectomy was performed, resecting all the tissue seated between the phrenic nerves from the xiphoid process to the innominate vein. Intra-operative PTH levels confirmed biological cure of primary hyperparathyroidism (Figure 4). The resected specimen was placed in an extraction bag within the mediastinum and removed through the subxiphoid incision. The incision was closed without placing a chest drain after exsufflation of the pleural cavities (Figure 5). The operative time was 103 minutes. The intervention was uneventful and estimated blood loss was $0 \mathrm{ml}$. The patient was discharged on postoperative day 1 in good general conditions with normal corrected serum calcium level $(2.41 \mathrm{mmol} / \mathrm{L})$ and PTH $(2.14 \mathrm{pmol} / \mathrm{L})$, without any pain medication. At final pathology, the parathyroid adenoma measured $25 \times 11 \times 6 \mathrm{~mm}^{3}$ and weighed $1.4 \mathrm{~g}$ (Figure 6).

\section{Discussion}

Ectopic mediastinal adenomas are most frequently encountered in the thymic tissue (6). Surgical excision of these glands is reported to be difficult by a cervical 
approach. Traditionally, median partial or complete sternotomy has been preferred for the accuracy in tumor identification and the good operative view $(7,8)$. The use of subxiphoid approach for resection of an ectopic mediastinal parathyroid gland was firstly reported by Kido et al. in 1999 (9). The authors reported good visual operative field and several advantages over conventional median sternotomy or thoracoscopy, particularly with regard of lower morbidity and better cosmetic outcomes. In recent years, advancements in $\mathrm{CO}_{2}$ insufflation and new surgical instrumentations provided an even wider frontal view of the anterior mediastinum improving operability with subxiphoid techniques $(10,11)$. Similarly, to conventional median sternotomy, subxiphoid approach now allows to clearly visualize the anatomical borders of resection, in particular both phrenic nerves and the left innominate vein which are critical structures to be preserved during dissection maneuvers. These benefits may be more arduous to obtain with standard VATS techniques which are limited by the incomplete view of mediastinum. With regard of postoperative pain, subxiphoid incision seems to be better tolerated by the patients compared to thoracoscopy for which chronic post-operative pain may occur variably from $11 \%$ to $80 \%$ of cases, similarly to open thoracotomy (12). This is particularly true when xiphoid process is not resected, even for removal of large and invasive mediastinal masses or pulmonary lobes $(13,14)$. In fact, it avoids injury to intercostal nerves and ribs spreading; also, abdominal incision does not interfere with thoracic movements postoperatively, during deep breaths or cough. Further reduction of pain from the intercostal spaces may be achieved if chest drain is placed subxiphoid. Additionally, by using this approach, no single-lung ventilation is required, favoring the patients with severe lung disease or poor pulmonary function (14). Finally, uniportal subxiphoid approach offers a relevant cosmetic advantage with an associated low risk of incisional hernia (13).

Using subxiphoid approach to operate in a narrow space as the anterior mediastinum, in adjacency to the heart beating and with the incomplete lungs collapse, due to single-lumen lung ventilation, is technically challenging and it requires familiarity with the single-port surgical procedure. However, insufflation of $\mathrm{CO}_{2}$ allowed more working space and dedicated 5 - $\mathrm{mm}$ instrumentation facilitated dissection maneuvers. Additionally, the use of GelPOINT $^{\circledR}$ offered greater freedom of movement and instrument articulation due to the specific design of the platform, thus maximizing the internal working space. In contrast, the subxiphoid approach has limited visibility to the lower poles of the thymus, nearby the hemi-diaphragms. When a more complete and aggressive resection is indicated, the implementation of a 5 -mm thoracoscope in the chest may allow, simultaneously, visualization of the entire anterior mediastinum (15). Further limitation of uniportal subxiphoid technique might be of entering the retrosternal space in a patient who underwent previous sternotomy or surgery in the anterior mediastinum.

Subxiphoid technique for resection of an intra-thymic parathyroid adenoma is feasible and safe. Thus, it may be considered a valid alternative to intercostal VATS possibly resulting in more favorable outcomes, particularly regarding postoperative pain. The subxiphoid approach may preferred in patients with an adenoma located below the left innominate vein, as shown in the cases treated using median sternotomy by Kitada and Abbas $(7,8)$. However, for ectopic glands found in the neck region or in the upper-anterior mediastinum a cervical approach is reasonable. Further investigations are still warranted to assess the advantages of using subxiphoid incision over conventional techniques.

\section{Acknowledgments}

Funding: None.

\section{Footnote}

Conflicts of Interest: All authors have completed the ICMJE uniform disclosure form (available at https://jovs. amegroups.com/article/view/10.21037/jovs.2019.12.04/ coif). FT reports personal fees from Stryker/Novadaq (travel fees), personal fees from Medtronic (travel + consulting fees), outside the submitted work. The other authors have no conflicts of interest to declare.

Ethical Statement: The authors are accountable for all aspects of the work in ensuring that questions related to the accuracy or integrity of any part of the work are appropriately investigated and resolved. All procedures performed in this study were in accordance with the Helsinki Declaration (as revised in 2013). Written informed consent was obtained from the patient for publication of this manuscript and any accompanying images.

Open Access Statement: This is an Open Access article distributed in accordance with the Creative Commons Attribution-NonCommercial-NoDerivs 4.0 International 
License (CC BY-NC-ND 4.0), which permits the noncommercial replication and distribution of the article with the strict proviso that no changes or edits are made and the original work is properly cited (including links to both the formal publication through the relevant DOI and the license). See: https://creativecommons.org/licenses/by-nc-nd/4.0/.

\section{References}

1. Soler R, Bargiela A, Cordido F, et al. MRI of mediastinal parathyroid cystic adenoma causing hyperparathyroidism. J Comput Assist Tomogr 1996;20:166-8.

2. Alesina PF, Moka D, Mahlstedt J, et al. Thoracoscopic removal of mediastinal hyperfunctioning parathyroid glands: personal experience and review of the literature. World J Surg 2008;32:224-31.

3. Said SM, Cassivi SD, Allen MS, et al. Minimally invasive resection for mediastinal ectopic parathyroid glands. Ann Thorac Surg 2013;96:1229-33.

4. Gerner P. Postthoracotomy pain management problems. Anesthesiol Clin 2008;26:355-67.

5. Castiglioni M, Karenovics W, Triponez F, et al. Uniportal subxiphoid approach for resection of an intra-thymic parathyroid adenoma: a case report. Asvide 2019;7:046. Available online: http://www.asvide.com/watch/33086

6. Wang C, Gaz RD, Moncure AC. Mediastinal parathyroid exploration: a clinical and pathologic study of 47 cases. World J Surg 1986;10:687-95.

7. Kitada M, Yasuda S, Nana T, et al. Surgical treatment

doi: 10.21037/jovs.2019.12.04

Cite this article as: Castiglioni M, Karenovics W, Triponez F, Bédat B. Uniportal subxiphoid approach for resection of an intrathymic parathyroid adenoma: a case report. J Vis Surg 2020;6:23. for mediastinal parathyroid adenoma causing primary hyperparathyroidism. J Cardiothorac Surg 2016;11:44.

8. Abbas F, Biyabani SR, Memon A, et al.

Mediastinal Parathyroid Adenoma causing primary Hyperparathyroidism. J Pak Med Assoc 2007;57:93-5.

9. Kido T, Hazama K, Inoue $Y$, et al. Resection of Anterior Mediastinal Masses Through an Infrasternal Approach. Ann Thorac Surg 1999;67:263-5.

10. Suda T, Sugimura H, Tochii D, et al. Single-Port Thymectomy Through an Infrasternal Approach. Ann Thorac Surg 2012;93:334-6.

11. Suda T. Uniportal subxiphoid video-assisted thoracoscopic thymectomy. J Vis Surg 2016;2:123.

12. Song $\mathrm{N}$, Zhao D, Jiang L, et al. Subxiphoid uniportal video-assisted thoracoscopic surgery (VATS) for lobectomy: a report of 105 cases. J Thorac Dis 2016;8:S251-7.

13. Dunning J, Elsaegh M, Nardini M, et al. Microlobectomy: a novel form of endoscopic lobectomy. Innovations (Phila) 2017;12:247-53.

14. Zhao J, Wang J, Zhao Z, et al. Subxiphoid and subcostal arch thoracoscopic extended thymectomy: a safe and feasible minimally invasive procedure for selective stage III thymomas. J Thorac Dis 2016;8 Suppl 3:258-64.

15. Yang HC, Coyan G, Vercauteren M, et al. Robotassisted en bloc anterior mediastinal mass excision with pericardium and adjacent lung for locally advanced thymic carcinoma. J Vis Surg 2018;4:115. 